\title{
Definition and Essence of Information
}

\author{
Tian-qing Qiao
}

\author{
whhbswdx@sina.com, Hubei Provincial Administration College, Hubei Wuhan, China
}

\begin{abstract}
It has been 60 years since the essential attributes of information were explored in the field of philosophy, resulting in many contentious schools of thought and a wide division of opinions. Some scholars in China and abroad have been trying to build a new system of information philosophy from an ontological perspective, so as to explain the world. In this paper, the author puts forward a definition of information and its mathematical expressions in order to demonstrate that information is the collection of three kinds of attributes of things. Analysis suggests that the essence of information is the interaction of matters and the representation of the law of causality in philosophy. The paper also explores the ways in which information-as a noun-is a term that people have customarily used and confused. Eventually, the induction, differentiation and utilization of information, as conventionally understood, should be applied into studying matters themselves.
\end{abstract}

Keywords: information, attribute, interaction, causality, Wiener

Acknowledgement: Prof. Carlos Aguilar and Prof. Lydia Sanchez have contributed a lot to polishing my article and giving valuable suggestions so that it is smoother and more readable. I want to extend my heartfelt gratitude to them.

In 1948, Wiener, founder of cybernetics, said: "Information is information, not matter or energy. No materialism which does not admit this can survive at the present day" (Wiener, 1948). Thus, he introduced the concept of information in the theory of communication to philosophy. Consequently, researchers and philosophers have been working to define the concept of information for 60 years. Statistics shows, there were about 130 definitions of information until 1980 (Gang, 2007, p. 71). As Claude E. Shannon (1916-2001), founder of information theory, suggested, "It is almost impossible to count on a sole concept about information being satisfactorily responsible for every possible application in general fields" (as cited in Gang, 2007, p. 71).

This paper puts forward a definition, as expressed mathematically, of what is customarily named information, hoping it will be helpful in putting to rest the philosophical search for a definition of the concept of information.

\section{Definition of information and its mathematical expressions}

Information, customarily understood, is the collection of three kinds of things' attributes: things themselves (including cause or effect formed through their interaction), the attributes of things that someone thinks and simulates, and the attributes of tools used when one considers, expresses, or simulates something. The first kind of attributes of things is based on facts, for example, the three physical states of water. These are physical, chemical, biological, social or any other properties of things, irrefutable and objective, and have nothing to do with any expressive connotations related to the thing (such as through spoken and written languages, music or pictures). The second kind of attribute is related to inner thoughts, or expressions through talk; namely, the second type of attributes of things is those that someone can find or that could be simulated through science and technology. Among these types of attributes, some are true to the facts and some are incomplete, while others are not in any way. The third kind of attributes are the attributes of tools used when someone (or something) thinks, expresses, or simulates something, i.e. the state of brain neurons when one thinks, the linear expression of words when one writes, the vibration frequency and intensity of sound when one speaks, the bit of circuit devices in a computer, or the models of devices used in an experiment, et cetera. Supposing that the sign $X$ represents the first kind of attributes, $X^{\prime}$ the 
second, and $\mathrm{X}_{\text {nffb }}$ the third, and info represents the information, we can simply express information with an array as below:

$$
\text { info }=\left(X^{\prime} X^{\prime} X_{\text {nlfb }}\right)
$$

or detailedly,

$$
\text { info }_{m}=\left(\begin{array}{cccccccccccc}
P_{m 1} & P_{m 2} & \cdots & P_{m n} & P_{m 1}^{\prime} & P_{m 2}^{\prime} & \cdots & P_{m n}^{\prime} & P_{n l f b m} & P_{n l f b m 2} & \cdots & P_{n l f b m n} \\
C_{m 1} & C_{m 2} & \cdots & C_{m n} & C_{m 1}^{\prime} & C_{m 2}^{\prime} & \cdots & C_{m n}^{\prime} & C_{n l f b m} & C_{n l f b m 2} & \cdots & C_{n l f b m n} \\
B_{m 1} & B_{m 2} & \cdots & B_{m n} & B_{m 1}^{\prime} & B_{m 2}^{\prime} & \cdots & B_{m n}^{\prime} & B_{n l f b m} & B_{n l f b m 2} & \cdots & B_{n l f b m n} \\
\cdots & \cdots & \cdots & \cdots & \cdots & \cdots & \cdots & \cdots & \cdots & \cdots & \cdots & \cdots \\
S_{m 1} & S_{m 2} & \cdots & S_{m n} & S_{m 1}^{\prime} & S_{m 2}^{\prime} & \cdots & S_{m n}^{\prime} & S_{n l f b m} & S_{n l f b m 2} & \cdots & S_{n l f b m n}
\end{array}\right)
$$

In the array, $P$ is for physical quality, $C$ the chemical quality, $B$ the biological quality, and $S$ the social quality, etc., instead of part of $X$, the attributes mentioned in the paper. What's more, $m$ is the number of various subsystems in a system, $m=1,2,3, \ldots$ and $n$ is the number of different qualities in every subsystem, $n=1,2,3, \ldots$

For example: The Hindu fable "The Blind Men and The Elephant". If one of the blind men A speaks English, B speaks Hindi, while C speaks Chinese, D speaks Russian.

Therefore,

$$
\begin{aligned}
& \operatorname{info}_{A}=(\text { elephant a pipe in English }) \\
& \text { info }_{B}=(\text { elephant a pillar in Hindi }) \\
& \text { info }_{C}=(\text { elephant wall in Chinese }) \\
& \text { info }_{D}=(\text { elephant a rope in Russian })
\end{aligned}
$$

The four pieces of information, the $X$ is the same, however, the $X^{\prime}$ or $X_{\text {nttb }}$ is different. Further examples include: the ingredients indicated on the packaging of a generic product are identical with those printed on the packaging to the same product produced by a well-known brand. A consumer, unaware that the sets of ingredients represent two different products, would think that the two sets belong to the same product. However, many of the physical, chemical, biological, social and other properties of the fake product will be entirely different from those of the brand-name product. Although the ingredients are all the same, the $X$ of the former product differs entirely from the $X$ of the latter, even though the fake and real products are alike in the $X^{\prime}$ and $X_{\text {nffb. }}$.

In order to make clear the conception of information described above, the expression of information, which is a natural phenomenon, are listed below:

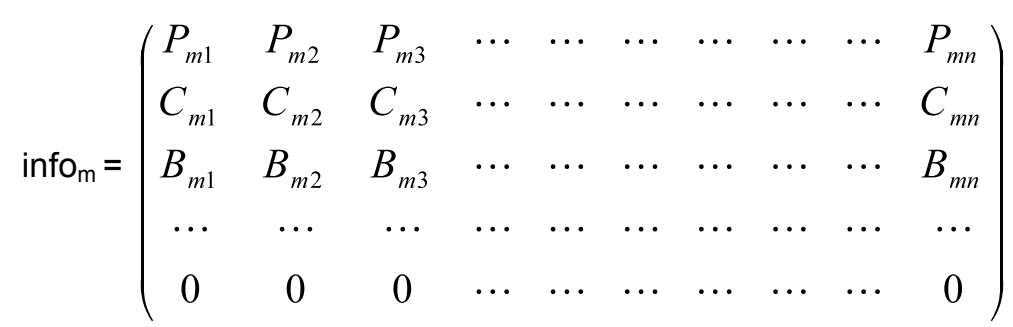

But the expression of information imparted in a lie Aesop's Fable "wolf is coming" should be as follows: 


$$
\text { Info }=(\text { no wolf wolf! In Hellenic })
$$

Information, as expressed in the transmission of words to the illiterate, as well as through abstract art and animals' sound for the vast majority of people, is expressed here:

$$
\text { info }_{m}=\left(\begin{array}{cccccccccccc}
0 & 0 & \cdots & 0 & 0 & 0 & \cdots & 0 & P_{n l f b m} & P_{n l f b m} & \cdots & P_{n l f b m n} \\
0 & 0 & \cdots & 0 & 0 & 0 & \cdots & 0 & C_{n l f b m} & C_{n l f b m 2} & \cdots & C_{n l f b m n} \\
0 & 0 & \cdots & 0 & 0 & 0 & \cdots & 0 & B_{n l f b m} & B_{n l f b m} & \cdots & B_{n l f b m n} \\
\cdots & \cdots & \cdots & \cdots & \cdots & \cdots & \cdots & \cdots & \cdots & \cdots & \cdots & \cdots \\
0 & 0 & \cdots & 0 & 0 & 0 & \cdots & 0 & 0 & 0 & \cdots & 0
\end{array}\right)
$$

Or words for the illiterate, abstract art and animals' sound can be shown as:

$$
\text { info }_{\mathrm{m}}=\left(\begin{array}{cccccccccccc}
P_{m 1} & P_{m 2} & \cdots & P_{m n} & 0 & 0 & \cdots & 0 & 0 & 0 & \cdots & 0 \\
C_{m 1} & C_{m 2} & \cdots & C_{m n} & 0 & 0 & \cdots & 0 & 0 & 0 & \cdots & 0 \\
B_{m 1} & B_{m 2} & \cdots & B_{m n} & 0 & 0 & \cdots & 0 & 0 & 0 & \cdots & 0 \\
\cdots & \cdots & \cdots & \cdots & \cdots & \cdots & \cdots & \cdots & \cdots & \cdots & \cdots & \cdots \\
0 & 0 & \cdots & 0 & 0 & 0 & \cdots & 0 & 0 & 0 & \cdots & 0
\end{array}\right)
$$

In the above two arrays, $X_{m n}=X_{\text {nffbmn }}$.

If you accept the above expressions, you can avoid a difficult position when attempting to define information in philosophy.

\section{Several worthwhile discussions}

Some scholars hold that it is necessary to distinguish "information in the sense of ontology" from "information in a sense of theory of knowledge" (Zhong, 2002).

Within the domain of philosophy, information should not have two definitions with different meanings, namely, definition in the sense of ontology and definition in a sense of a theory of knowledge. If one admits that information is an inconsistently used term, one will not attempt to treat it in philosophical or categorical terms..

Further, information in the domain of philosophy is not, as has been suggested, simply the indirect indication of existence, as the self-manifestation of matter's existence (direct existence) and its state (Kun, 2005).

If information is just the indirect indication of existence and matter's self manifestation, how can information produce a strong material force? Additionally, why does the power of information vary from person to person, and in its connection with objects? And why do people often fail to distinguish true information from false information and be deceived?

Some Chinese scholars have suggested that information has thus arisen as a concept as fundamental and important as "being", "knowledge", "life", "intelligence", "meaning" or "good and evil" (Floridi, 2002).

Body, being, substance, are different terms for the same reality. It is impossible to separate thought from matter that thinks. This matter is the substratum of all changes going on in the world (Engels, 1844, p. 164).

There seems an inclination of dualism in the author's viewpoint, which we do not agree with and as an account cannot explain why there exists a great deal of insignificant and boring junk messages. 


\section{Essence of information and correct research direction}

Those languages we can understand (including words we can read) convey information. But one cannot say that languages we cannot follow (including words we cannot read) have conveyed the same information, nor can one say the interpretations of such languages have conveyed the same information. Therefore, there is different interpreted information when we can understand a language or not.

When reading a book, seeing a movie, attending a lecture, or listening to music, someone may be moved or stirred, then one cannot say he does not communicate information with words, pictures and languages. When you explore the substances of words, pictures and languages, you may be aware that this is the changes between man and natural phenomena, and the communication between man and his social activities, but not the communication of information between the lines of words, the vibration frequency and intensity of sound in a language. If the same information is expressed in strange words and languages, or so-called aliens' art which man does not know, nobody is certainly moved or inspired.

Therefore, we can infer a conclusion: information, conventionally understood, is in fact the interaction among man, other beings and various matters. When they interact, different things have different information.

Information can be both material and mental, existing or conscious, produced or received, true or false, real or fictitious, right or wrong, remembered or forgotten, known or unknown; it can exist objectively but cannot be perceived subjectively, or vice versa; and it can be powerful or weak, have tangible or intangible value, and so on. True information is mingled with false, and sometimes it appears while sometimes it disappears. So, here is another conclusion: information, conventionally understood, is self-contradictory.

Wiener introduced the concept of information in the theory of communication to philosophy, a move that has been considered a breakthrough. However, he failed to anticipate complicated new ideas and technologies (emerging one after another in today's society) that have ultimately challenged our conception and definition of information. His ideas have been diluted by the myriad (and often confusing) ways in which people have used the concept of information. I am afraid that the study of information could be placed in the same difficult position as when people were seeking "the ether" at the end of the 19th century. As a result, the academic community has been unable to reach a consensus as to the meaning and definition of information.

Focusing on the attributes of things (including beings), we are able to resolve the contradiction inherent in information, as commonly understood, by distinguishing information from the various attributes of things. For example, the instruction of a generic product is the same as that of a brand-name product, but the function of the generic product is not the same as the brand-name one.

Presently, the concept of information remains self-contradictory and confusing. One is certain to run into problems while trying to give a philosophical or scientific definition of information. It is impossible to state the precise ontological meaning of "information", just as one language, English or Esperanto, is unable to unify 4300 languages in the world.

Information, customarily understood, is essentially the most ancient interaction in nature, so, as in Hegel (1976, pp. 203-223), interaction is the ultimate cause of matter and interaction happens only between attributes of things.

Languages and words are tools to distinguish between things themselves or connections between them. Customarily-stated information which languages and words convey lags behind the attributes of things which result in customarily-stated information. A thing is cause whereas a language is effect. Viewed from causality according to time priority order, effect certainly lags behind cause, too. When someone speaks, his sound is not the thing it expresses or describes. Language functions to express matters only when it forms the corresponding mechanism in man's brain. Language exists both as an artifact in the external world - a collection of symbols in admissible combinations-and as the embodiment in the brain of those symbols and the principles that deter- 
mine their combinations. The brain uses the same machinery to represent language that it uses to represent any other entity. As neuroscientists come to understand the neural basis for the brain's representations of external objects, events and their relations, they sill simultaneously gain insight into the brain's representation of language and into the mechanisms that connect the two. (Damasio \& Damasio, 1992).

All in all, there is only the interaction between (attributes of) things. Information is just a noun people have customarily used and abused. Eventually, the induction, differentiation and utilization of customarily named information will be applied into studying things themselves. The sole criterion for testing truth is practice.

\section{References}

Crick, F. (1994). The astonishing hypothesis: The scientific search for the soul. New York, NY: Charles Scribner's Sons. Damasio, A. R. \& Damasio, H. (1992). Brain and language. Scientific American, 267, 89-95.

Floridi, L. (2002). What is the philosophy of information? Metaphilosophy, 33, 123-145.

Engels, F. (1844): Socialism: Utopian and scientific. In K. Marx \& F. Engels (1965), Complete Works of Marx and Enge/s (Vol. 2). Beijing: People's Publishing House.

Gang, L. (2007). An inquiry into the origin of the philosophy of information. Beijing: JinCheng Press.

Hegel, G. W. F. (1976). Logic (Vol. 2). Beijing. Commercial Press.

Shannon, C. E. (1993). Collected Papers. N. J. A. Sloane \& A. D. Wyner, (Eds.). Los Alamos, CA: IEEE Computer Society Press

Wu, K. (2005). Information philosophy: Theory, system, method. Beijing: Commercial Press.

Zhong, Y. (2002). Principles of information science. Beijing: Beijing University of Posts and Telecommunications Press.

\section{About the Author}

Tian-qing Qiao

Retired teacher of Hubei Provincial Administration College; former professor in philosophy of science and tutor for master degree gainer; leader of the project "Computer Endues Dialectical Materialism with New Meaning of the State" funded by the Social Science Fund in 1999 (Confirmation No : 99BX018); gave special lectures entitled "What Is Information?" in Hubei Library and Wuhan Library. 